\title{
Effect of the Diameter Ratio on the Flexural Stress of Carbon Fibre Composite Rod
}

\author{
Chunyu Jiang* \\ Institute of Maritime, Dalian Maritime University, Liaoning Province, P.R. China \\ ${ }^{*}$ Corresponding author
}

\begin{abstract}
Carbon fibre composite rod (CFCR) is an important part during the design of Aluminum Conductor Composite Core (ACCC) conductor. CFCR is used to improve the bearing capacity in order to make sure the safety of electric power supply. The flexural failure of CFCR could lead to the outage of electric power. Therefore, it is important to investigate the flexural behavior of CFCR. The diameter of CFCR and the diameter of wheel have a great effect on the flexural failure of CFCR. This paper presents a finite element model (FEM) to analyze the stress in CFCR under flexural loading. Based on the proposed FEM, the effect of diameter ratio on the flexural stress of CFCR is analyzed. Using the calculated results, the variation of flexural stress with the diameter ratio is obtained. These conclusions would help to design Aluminum Conductor Composite Core (ACCC) conductor.
\end{abstract}

Keywords - carbon fibre composite rod; flexural stress; finite element model; diameter ratio

\section{INTRODUCTION}

Aluminum Conductor Composite Core (ACCC) conductors have been widely in electric power [1-3]. ACCC is composed by the strong and light composite core surrounded by strands of annealed Aluminum [4]. Because Carbon fibre composite rod (CFCR) possesses high strength and low density, it is usually chosen to be the composite core [5]. The carbon fibre composite rod is consisted of continuous carbon fibres embedded in a high temperature epoxy [6, 7]. CFCR needs high bearing capacity during the operation of electric power [8]. The flexural failure of CFCR could result in the outage of electric power. Therefore, high flexural properties are necessary for CFCR to avoid the outage of electric power.

The flexural mechanical properties of carbon fibre composite (CFC) have been extensively investigated to promote the application of CFC [9-12]. An analytical and finite element modeling approach was proposed to predict the effective mechanical properties of a composite conductor [13]. The failure process of hybird composite rods was analyzed by using acoustic emissions and subsequent Scanning Electron Microscope (SEM) [14]. Mujika et al. proposed an experimental procedure for determining flexural, tensile and compressive modulus [15]. The compressive strength of unidirectional composites was obtained by three-point bending tests [16]. Analytical expressions were derived to obtain the normal and shear stress distributions in a three-point bending test [17]. Di Landro et al. found that defects, such as voids and delaminations, significantly reduced the mechanical performance of components made of composite laminates [18]. The change in mechanical properties like tensile strength and hardness were investigated by changing the percentage composition of carbon by $30 \%, 35 \%$ and $45 \%$ in the carbon epoxy composite [19]. The improvements in the mechanical properties at different composition of carbon aramid hybrid fibres were studied by changing the percentage composition of carbon-aramid hybrid fibres [20]. Recently, it is found that both flexural flow stress and fracture strain increase by adding various concentrations of nanotube [21].

The fantastic pioneer studies have concentrated on the failure process and stress distribution of CFCR under flexural loading. However, the effect of CFCR diameter and wheel diameter on the flexural stress of CFCR has not been researched. In this work, we propose a finite element model (FEM) to predict the flexural mechanical properties of CFCR. We focus on the variation of flexural stress with the diameter ratio.

The organization of this paper is the following: Section 2 describes the finite element model of CFCR under flexural loading in detail. The effect of diameter ratio on the flexural stress is presented in Section 3. Finally, Section 4 gives remarkable conclusions of this work.

\section{Finite ELEMENT MODEL}

Figure I shows the geometrical modeling of CFCR under flexural loading. CFCR with a diameter of is bended by attaching on the surface of wheel. The geometry sizes for all of the models used here are illustrated in Table I. A 3D FEM can be set up (Figure II) accounting for the geometry size in Table1.

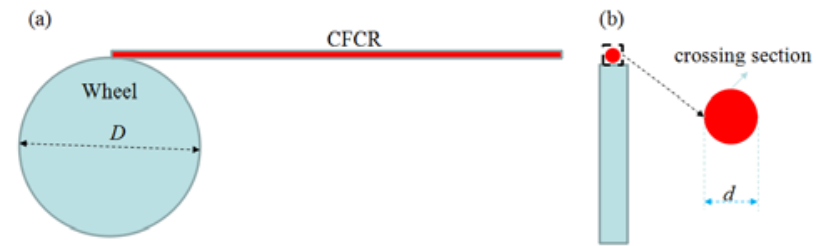

FIGURE I. GEOMETRICAL MODELING OF CFCR: (A) FRONT VIEW; (B) SIDE VIEW 


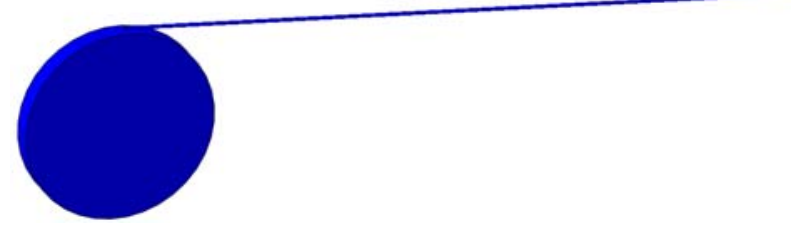

FIGURE II. 3D FINITE ELEMENT MODEL

TABLE I. GEOMETRY SIZES FOR ALL OF THE MODELS

\begin{tabular}{ccc}
\hline $\begin{array}{c}\text { No. of } \\
\text { model }\end{array}$ & $\begin{array}{c}\mathrm{d} \\
(\mathrm{mm})\end{array}$ & $\begin{array}{c}\mathrm{D} \\
(\mathrm{mm})\end{array}$ \\
\hline 1 & 5 & 500 \\
2 & 10 & 500 \\
3 & 15 & 500 \\
4 & 20 & 500
\end{tabular}

CFCR consists of a T700 carbon fibre composite (CFC). The matrix of CFC is a cycloaliphatic high temperature epoxy resin. The volume fraction of carbon fibre in CFC is 55\%. For aligned fibres, fibres and matrix are subjected to the same uniform strain in the fibre direction. Voigt [22] got the effective modulus in the fibre direction as:

$$
E_{L}=V_{f} E_{f}+\left(1-V_{f}\right) E_{m}
$$

Reuss [23] applied the same uniform stress on the fibre and matrix in the transverse direction (normal to the fibre direction), and got the effective modulus in the transverse direction as:

$$
\frac{1}{E_{T}}=\frac{V_{f}}{E_{f}}+\frac{1-V_{f}}{E_{m}}
$$

where $V_{f}$ is the volume fraction of fibre in the two-phase composite system, subscripts $\mathrm{f}$ and $\mathrm{m}$ refer to the fibre and matrix respectively, and subscripts $\mathrm{L}$ and $\mathrm{T}$ refer to the longitudinal and transverse directions respectively.

According to Eq. (1)-(2), the material properties should be considered in two different directions. The material properties used in FEM are set as an elastic material. The modulus elasticity and Poisson's ratio of CFC materials can be seen in Table II.

\section{TABLE II. MODULUS ELASTICITY AND POISSON'S RATIO OF CFC MATERIALS}

\begin{tabular}{ccccc}
\hline Material & $E_{L}(\mathrm{GPa})$ & $E_{T}(\mathrm{GPa})$ & $v_{L}$ & $\nu_{T}$ \\
\hline CFC & 158 & 15 & 0.3 & 0.3 \\
\hline
\end{tabular}

Model was meshed by elements defined by 8 nodes with 3 degrees of freedom in tetrahedral bodies. The linear hexahedral element of C3D8R was employed in these simulations. The model consisted of approximately 4721 elements and 6033 nodes. The center of the wheel in Figure I was hinged and one side of CFCR was fixed on the circumference of the wheel. Therefore, CFCR can be twined on the circumference of the wheel when the wheel rotates. When the calculations have been accomplished, the Mises stresses are obtained by means of output databases. Based on the calculated Mises stresses, the mechanical properties of CFCR can be analyzed.

\section{SiMULATED RESUltS}

Based on the proposed FEM, the numerical simulation of CFCR subjected to pure bending loading was conducted. Figure III shows the calculated results from finite element model for the CFCR diameter of $10 \mathrm{~mm}$. There is a stress distribution in the materials which have gone into the pure bending loading zone; however, the materials without going into wheel are free of stress. According to the enlarged view of the CFCR in pure bending zone, the stress distribution is not uniform. The Mises stress in the center is less than that in outer zone. There is a stress gradient from internal surface to outer surface. The maximum stress of $\sim 2.66 \mathrm{GPa}$ appears in the outside surface of CFCR, whose diameter is $10 \mathrm{~mm}$.

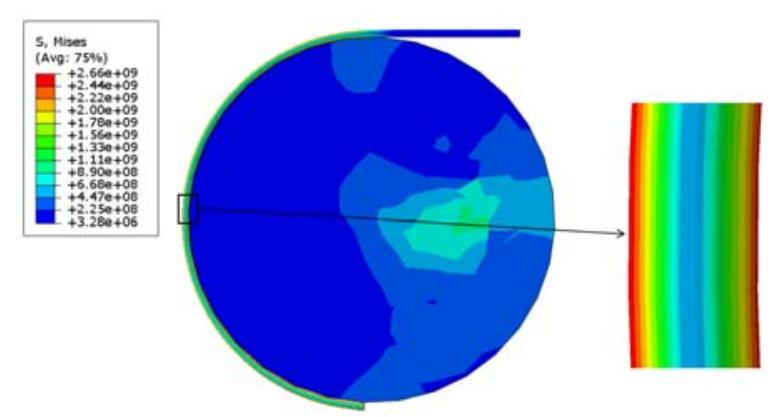

FIGURE III. STRESS NEPHOGRAM AFTER SIMULATION

In order to reveal the mechanism of elastic deformation in CFCR, the FEM simulations were carried out at different CFCR diameters. Figure IV illustrates the Mises stress-time curves for different CFCR diameters. With the rotation of the wheel, the Mises stress increases greatly at the beginning of twining, but the Mises stress is nearly a certain value if CFCR twines on the circumference of the wheel completely. As shown in Figure IV, the stable Mises stress increases with the increasing CFCR diameter. CFCR with larger diameter possesses larger bending inflexibility, so larger mechanical response is obtained at the same bending condition $(\mathrm{D}=500 \mathrm{~mm})$. Mises stress changes from 2.61 GPa to $3.45 \mathrm{GPa}$ if diameter ratio changes from $1 \%$ to $4 \%$. The failure stress of CFC is $\sim 2.8 \mathrm{GPa}$; therefore, CFCR with the diameter of $5 \mathrm{~mm}$ and $10 \mathrm{~mm}$ cannot be destroyed under pure bending in the wheel diameter of $500 \mathrm{~mm}$. As for the CFCR diameter of $15 \mathrm{~mm}$ and $20 \mathrm{~mm}$, the stable Mises stress would be larger than the failure stress, so CFCR can not undergo the twining of wheel with the diameter of $500 \mathrm{~mm}$. 


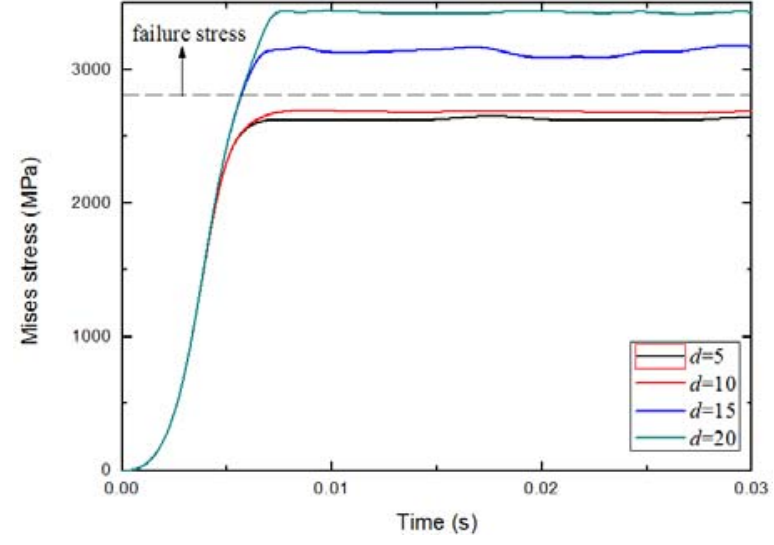

FIGURE IV. MISES STRESS VERSUS TIME AT DIFFERENT DIAMETER RATIOS

\section{SUMMARY}

Based on the theory of transverse isotropy materials, a 3D finite element model (FEM) is proposed to research the flexural behavior of carbon fibre composite rod (CFCR). According to the simulated results, the Mises stress in outer surface is larger than that in internal surface. The maximum of Mises stress increases with the increasing diameter of CFCR if the diameter of wheel is a fixed value. If the diameter ratio of wheel to CFCR is less than 50, material failure would be happen during the flexural deformation of CFCR.

\section{ACKNOWLEDGEMENT}

This work has been supported by Fundamental Research Funds for undergraduates.

\section{REFERENCES}

[1] Alawar, E. J. Bosze, S.R. Nutt, A composite core conductor for low sag at high temperatures. IEEE Transactions on Power Delivery. 20 (2005) 2193-2199.

[2] B. Burks, J. Middleton, M. Kumosa, Micromechanics modeling of fatigue failure mechanisms in a hybrid polymer matrix composite. Composites Science and Technology. 72 (2012) 1863-1869.

[3] J. Hoffman, J. Middleton, M. Kumosa. Effect of a surface coating on flexural performance of thermally aged hybrid glass/carbon epoxy composite rods. Composites Science and Technology. 106 (2015) 141-148.

[4] J. Middleton, J. Hoffman, B. Burks, P. Predecki, M. Kumosa , Aging of a polymer core composite conductor: Mechanical properties and residual stresses. Composites Part A: Applied Science and Manufacturing. 69 (2015) 159-167.

[5] J. Middleton, B. Burks, T. Wells, A.M. Setters, I. Jasiuk, M. Kumosa, The effect of ozone and high temperature on polymer degradation in polymer core composite conductors. Polymer Degradation and Stability. 98 (2013) 2282-2290.

[6] K. Kopsidas, S. Rowland, A performance analysis of reconductoring an overhead line structure. IEEE Transactions on Power Delivery. 24 (2009) 2248-2256.

[7] A.K. Pathak, M. Borah, A. Gupta, T. Yokozeki, S.R. Dhakate, Improved mechanical properties of carbon fiber/graphene oxide-epoxy hybrid composites. Composites Science and Technology. 135(2016) 28-38.

[8] K. Naito, H. Oguma, Tensile properties of novel carbon/glass hybrid thermoplastic composite rods. Composite Structures. 161(2017) 23-31.
[9] K. Shirvanimoghaddam, S.U. Hamim, A.M. Karbalaei, S.M. Fakhrhoseini, H. Khayyam, A.H. Pakseresht, Carbon fiber reinforced metal matrix composites: Fabrication processes and properties. Composites Part A: Applied Science and Manufacturing. 92 (2017) 70-96.

[10] S. Ropers, M. Kardos, T.A. Osswald, A thermo-viscoelastic approach for the characterization and modeling of the bending behavior of thermoplastic composites. Composites Part A: Applied Science and Manufacturing. 90 (2016) 22-32.

[11] Y. Zhang, Y. Li, H. Ma, T. Yu, Tensile and interfacial properties of unidirectional flax/glass fiber reinforced hybrid composites. Composites Science and Technology. 88 (2013) 172-177.

[12] [12] K.L. Pickering, M.G.A. Efendy, T.M. Le. A review of recent developments in natural fibre composites and their mechanical performance. Composites Part A: Applied Science and Manufacturing. 83(2016) 98-112.

[13] W. Sun, J.T. Tzeng, Effective mechanical properties of EM composite conductors: an analytical and finite element modeling approach. Composite Structures. 58 (2002) 411-421.

[14] B.M. Burks, D.L. Armentrout, M. Baldwin, J. Buckley, M. Kumosa, Hybrid composite rods subjected to excessive bending loads. Composites Science and Technology. 69 (2009):2625-2632.

[15] F. Mujika, N. Carbajal, A. Arrese, I. Mondragon, Determination of tensile and compressive moduli by flexural tests. Polymer Testing. 25 (2006) 766-771.

[16] N. Carbajal, F. Mujika, Determination of compressive strength of unidirectional composites by three-point bending tests. Polymer Testing. 28 (2009) 150-156.

[17] M.C. Serna Moreno, A. Romero Gutiérrez, J.L. Martínez Vicente, Different response under tension and compression of unidirectional carbon fibre laminates in a three-point bending test. Composite Structures. 136 (2016) 706-711.

[18] L. Di Landro, A. Montalto, P. Bettini, S. Guerra, F. Montagnoli, M. Rigamonti, Detection of voids in carbon/epoxy laminates and their influence on mechanical properties. Polymer and Polymer Composites. 25 (2017) 371-380.

[19] S. Blaise, D. George, K. Shunmugesh, K.T. Akhil, The effect of fibres loading on the mechanical properties of carbon epoxy composite. Polymer and Polymer Composites. 25 (2017) 237-240.

[20] C. Genuvin, P. Bins, K.T. Akhil, K. Shunmugesh, The effect of fibre loading on the mechanical behaviour of carbon aramid hybrid composites. Polymer and Polymer Composites. 25 (2017) 225-228.

[21] C. Yang, Y. Lee, T. Hsieh, T. Chen, T. Cheng, Mechanical property of multiwall carbon nanotube reinforced polymer composites. Polymer and Polymer Composites. 26 (2018) 99-104.

[22] W. Voigt, Uber die beziehung zwischen den beiden elasticitatsconstanten isotroper korper. Ann Phys. 38 (1889) 573-587.

[23] A. Reuss, Berechnung der fliebgrenze von mischkristalen auf grund der plastizitatsbedingung fur einkristalle. ZAMM. 9 (1929) 49-58. 